\title{
Is education's past its 2050 prologue? $^{1}$
}

\author{
William H. Graves ${ }^{2}$ \\ Ellucian, Fairfax, VA, USA \\ E-mail:Bill.Graves@ellucian.com
}

I ask you to consider the future of education, especially of postsecondary education. If you choose to extrapolate from familiar paragons of academic excellence, you may gloss over a challenging policy conundrum. Progressive leaders around the world are asking for help from education leaders. Their policy goal is to scale up, often to unprecedented levels, the intellectual-capital pool of postsecondary credentialed adults. They also want the scaling process to address pressing workforce and economic development needs that often depend on expertise in science, technology, engineering and mathematics (STEM) - or their applications.

The observations that follow suggest that the demographic, economic and cooperative dimensions of scaling present a conundrum unlikely to be resolved by extrapolating forward with ongoing incremental improvements to today's credentialing paradigms. Indeed, I argue that new paradigms will be needed and will require technology-enabled redesigns of economic governance and information governance of the credentialing market.

\section{Educational attainment}

We, the higher educated, must globally grow our ranks in order to resolve threats to the common good, thereby building enough trust to make intellectual capital itself a common good. Hoping for such a virtuous cycle, H.G. Wells wrote in 1920 that, "Human history becomes more and more a race between education and catastrophe".

Over 90 years later, education is more important than ever, not only to its internal stakeholder groups, but also to external stakeholder "investors" - students, parents, governments, donors, employers and suppliers. Indeed, external investors are expecting their collective investments in organized learning to yield far more than the aggregate of the private returns that accrue to individuals who complete a trusted postsecondary degree or certificate. People with advanced learning want advanced jobs, and advanced jobs "want" people with advanced learning! Equal-opportunity governments want both! We need more lifetime learners who can add value not only to the churning global economy and polity, but also to

\footnotetext{
${ }^{1}$ This work is licensed under the Creative Commons Attribution-Noncommercial No Derivations Works 3.0 Unported license. You are free to Share this work (copy, Distribute and transmit) under the following conditions: attribution, noncommercial and no derivative works. To view a copy of this license, visit http://creativecommons.org/licenses/by-nc-sa/3.0/.

${ }^{2}$ Most of the evidence and logic that justifies the holistic thinking in this paper are in the author's two recent EDUCAUSE papers: (1) "Facing education's mounting challenges with collaboration and IT", ECAR Research Bulletin 5 (2011), *http://net.educause.edu/ir/library/pdf/ERB1105.pdf+ and (2) "Waste not the learning productivity crisis: transforming educational opportunity into educational assurance", EDUCAUSE Review 45(1) (January/February 2010), Web Bonus (http://net.educause.edu/ir/library/pdf/ERM1014.pdf). The first of these papers addresses the need for new forms of cooperation and collaboration and then proceeds to lay the foundation for this paper and others.
} 
the deepest expressions of learning: the research discoveries and resulting innovations that create new value in the economy and in the common good. Advanced learning accordingly must become a common good - both a public and private good - that ranks in importance alongside the world's inter-connected economies and ecosystems and individuals' physical health and security. In this context, educational attainment - the proportion of an adult demographic holding a trusted postsecondary credential (degree or certificate) - is a rational proxy for the capacity to avert or mitigate Wells' catastrophes, while striving always to advance and sustain social, economic and environmental justice.

\section{Some conundrums of the attainment challenge}

To muse on the attainment challenge in your geopolitical context, substitute the relevant data (for the US data) in the following interconnected observations:

(1) Various policy and business leaders in the US, including President Obama, are supportively pressuring education leaders to scale up the proportion of adults who hold an accredited postsecondary credential (a trusted degree or certificate) from $40 \%$ to $60 \%$ over the next $10-15$ years - thereby swelling the population of credentialed adults from around 80 million to over 120 million, which is a tall order.

(2) Were the $40 \%$ proportion to scale up to $60 \%$ by 2020 - President Obama's original goal in 2010 then it would have increased at an exponential rate averaging at least $4.1 \%$ per year. In the process:

(a) Today's copiously leaky lifelong education pipeline would have scaled up in absolute terms to enable an increase in the attainment proportion from $40 \%$ to $60 \%$ of the adult population.

(b) The proportion of low- and middle-income students in the pipeline would have increased in response to prevailing economic demographic trends.

(c) Funding demands for needs-tested student grants and loans accordingly would have increased and thereby further exacerbated today's conundrum of three-way affordability:

(i) affordability of net tuitions or net credential costs to the growing proportion of low- and middle-income students and families,

(ii) affordability to governments and other funding sources of their investments in making education more affordable to these same students and families, and

(iii) affordability of the operating costs incurred by institutions offering credentialing "opportunities" in which both tuition pricing and presumed quality are based on credit hours, thus forcing net tuition upward in response to a growing proportion of needy-student enrollments and declining per-student contributions from government.

(3) Annual credential completion rates are not necessarily a proxy for national attainment rates! In spite of concerted efforts - many successful - to improve annual credentialing rates at the institutional level, annual national attainment proportions have stagnated at around $40 \%$ for at least three decades.

(4) There is no evidence that incremental, continuous quality improvements in annual credentialing rates at the institutional level will automatically aggregate up to improve upon attainment proportions at the targeted regional, national or global scale. Widespread, achievable improvements in credentialing rates at micro levels may not improve attainment rates at targeted macro level! 


\section{Think globally, act locally: A necessary but not sufficient strategy}

The preceding overview analysis will vary from one geopolitical context to another. Key variables include population size, growth rates and economic demographics, along with initial attainment proportions and targeted attainment goals. Several structural issues nevertheless emerge to give pause to educators and policy leaders who are focused only on extrapolating to increased credentialing rates in their contexts. These issues include the following ones:

(1) The three-way affordability conundrum must be resolved in order for education and its external investors to share equitably in the total expense and benefits of educational attainment at scale.

(2) Attainment proportion and credentialing rate are different metrics. Credentialing rates are but one variable in any dynamical system of attainment proportions that depends on collective results from thousands of institutions. Little is known about what realistically achievable average annual credentialing rate, if any, might lead to a targeted attainment proportion during a targeted period of time. Consider that the Lumina Foundation's Goal 2025 is "to increase the proportion of Americans with high quality degrees and credentials to $60 \%$ by 2025 ". Lumina recently announced that $38.3 \%$ of working-age Americans (ages 25-64) held a two- or four-year college degree in 2010, which is up only modestly from 2009 , when the rate was $38.1 \%$, and from 2008 , when the rate was $37.9 \%$. These results defy well-intended, ongoing work to improve credentialing rates.

(3) Improving attainment proportions is a dynamical systems challenge that should be studied to understand which interventions predict targeted attainment proportions within the constraints of threeway affordability.

(4) Student success (improvements in institutional persistence and credentialing rates) is necessary but not sufficient for institutional success.

(5) Institutional success is necessary but not sufficient for national success (or success at other macro levels of meeting attainment challenges).

\section{Attainment at scale: Consumerizing the credentialing marketplace}

Closing the financial and scaling gaps in the common-good attainment challenge will not be easy, especially when so many institutions aspire to join the top ranks of today's paragons of academic excellence. Only ten institutions, after all, appear in any top-ten list! Large endowments or wealthy oligarchies and monarchies may permit a few institutions to serve a well prepared student body with practices and processes coveted by, but not affordable at, most other institutions. The vast majority of tuition-dependent institutions, and even some well-endowed public universities, are constrained by public charters and/or limited external support. These majority institutions, especially the public ones, are expected to become the engine for scaling up attainment. They will thrive only by proactively playing a major role, alongside government, in improving the three-way affordability of net tuition to low- and middle-income students and of the expenditures to the institutions and governments that together subsidize that growing student low- and middle-income economic demographic. The credentialing marketplace accordingly needs to become a consumer marketplace in order to serve the growing ranks of needy and middle-class students. Consumerization can be addressed through a number of strategies, some involving extrapolation and some involving more progressive, non-incremental innovations. 


\section{Adult learner strategy}

In many nations, the adult population itself is one key to scaling up attainment. Many adults want or need affordable access to a trusted credentialing market, whether in pursuit of a first credential or an additional credential from which to improve upon their socioeconomic status or empower their contributions to the world.

\section{6. "Flexing” for institutional/personal optimization of high-tech/high-touch}

We already know that credentialing programs that use the leverage of technology can be as effective and efficient as traditional programs. By being more purposeful about costs and flexibility, however, more can be accomplished. The flex strategy provides a full array of scalable, online (asynchronous) academic and administrative self-services to all students, as a means to reduce per-student cost structures while focusing high-touch faculty efforts on designing and affordably delivering the individualized expert help that most students need (and expect) as they advance along a learning pathway tailored to meet individualized needs and circumstances. Self-service permits expertise to be reallocated to the more pressing needs of the individual student. The resulting personalized-credentialing mantra for student, faculty and institutional success might then read:

\section{High-tech self-service anytime; high-touch individualized help when needed.}

\section{Competency-based learning: Defying the tyranny of the credit hour}

Competency-based learning puts the focus on learning outcomes and their evaluation, rather than on access and credit hours compensated. Transitioning away from the credit hour as the basis for credentialing to individualized competency-based credentialing programs can combine with the flex strategy and other strategies described below to lead to more open and affordable credentialing paradigms. Competency-based credentialing thus presents an opportunity for improving trust in credentialing - by unbundling education into learning services and independent services for evaluating learning outcomes, at least those that are part of the common core of basic fluency and critical-thinking skills. Unbundling is at the heart of the trend to help students when they need help, which is the high-touch leg of the flex strategy and which can modularize and shorten the traditional course- and semester-based pathways to a credential.

\section{Common core redesign strategy}

A common curriculum of core knowledge and skills is broadly considered by educators to be a solid foundation for learning to learn and conducting a lifetime of learning. At various levels of experience and age, these skills and core content are required or highly recommended to almost all learners and represent a significant proportion of all enrollments worldwide. By using technology to redesign the common core and pathways through it, learned competencies and delivery costs structures can be improved. In combination with the other strategies touched upon here the common core redesign strategy can measurably improve learning readiness and, if learning competencies are independently evaluated, also improve the overall productivity and trustworthiness of attainment. The National Center for Academic Transformation has led and demonstrated the efficacy of this key strategy in the US and beyond. 


\section{Actionable accountability: Learning and attainment analytics}

We now know that learning analytics tools can help improve student success and learning outcomes. The concept uses predictive analytics and other forms of analysis to help institutions move beyond periodic summative reporting into more immediately actionable formative evaluations and interventions from the modular level to the course level to the institutional level. We also need attainment analytics tools (formative and summative) to help bridge the gaps in the pathways from student credentialing success to institutional success to national attainment success to global attainment success. The challenge is to formulate the questions and related indicators that can help measure the gap between, for example, institutional success and national attainment success. An even larger challenge, one that will determine how effective learning and attainment analytics can become, is the extraction of a student's data from various institutionally-proprietary systems into a distributed and privacy-secured unit-record database designed to give students full rights to their privacy-secured individualized, integrated educational record and to share any parts of that record at their discretion, whenever and wherever a lifetime of learning takes them. Analogous to a unit-record database in education is a digital, privacy-secured, personal health record that is under the control of the patient.

\section{0. "Flattening" strategies: External sourcing and institutional partnering}

In the global service economy, excepting the education and health care sectors, scale and consumer affordability have derived from innovations and service redesigns enabled by information technology. Productivity in the service economy has increased accordingly. To achieve similar results in postsecondary education, new forms of cooperation will be needed, first among faculty and administration and then among institutions willing to source non-core services externally or to share services with partner institutions. Thomas Friedman described external sourcing and partnering models as the flattening forces of out-sourcing, in-sourcing, work-flowing, supply-chaining, off-shoring, open-sourcing, in-forming and steroid-ing. These models have not been broadly used in the credentialing market, where flattening has been interpreted to refer to institutionally-sponsored study-abroad programs or to recruiting foreign students to a traditional campus or its branch campus(es) abroad.

By adopting and sharing a common platform of flex services (see above), perhaps to include massive, online, open courses and modules (see the examples below), cooperation among institutions can increase economies of scale and per-student productivity results for each institution. By acknowledging that scale is no longer the inverse of quality, shared-service collaborations have an advantage over stand-alone institutions.

\section{Examples of strategies in action}

The UK's Open University is a prescient, now mature and globally admired innovation. The OU has opened up tertiary access to low- and middle-income students (adults and otherwise), while also doing more than its part to scale up the proportion of adults holding postsecondary credentials. The OU also addresses attainment's escalating three-way affordability conundrum: the need to lower the costs of attainment not only to low- and middle-income students, but also to the institutions and governments that financially support them. 
The OU arose from rethinking teaching, learning, and credentialing in a context not unlike the interconnected challenges encoded here as the attainment conundrum/challenge. The result was a new institution, not the pursuit of incremental improvements to traditional credentialing practices among UK universities.

The OU, Athabasca University (Canada's Open University), and Western Governors University (WGU) in the US are making inroads into competency-based credentialing, in some cases coupled with independent learning evaluations. These institutions and others are learning how to credential learning that draws significantly on open educational resources (OER) - content and other resources openly and, typically, freely accessible. At an extreme of OER are massive online open courses/modules (MOOC) in which one expert or a network of cross-institutional experts facilitates learning among thousands, even hundreds of thousands, of students at one time. The OU's OpenLearn, the Khan Academy and ISKME's OER Commons are OER examples, while Connectivism and Connective Knowledge 2011 is an interesting MOOC from Athabasca University.

The Business Higher Education Forum in the US is a nonprofit, non-governmental organization that brings together business and higher education leaders, along with leadership from government and other nonprofit sectors, to work on selected issues that are central to the national attainment challenge from both a business and education perspective. Current BHEF initiatives focus on a range of attainment issues in STEM education and on college readiness more broadly. These initiatives rely on the strategy of thinking globally, while acting regionally. The BHEF, moreover, is a partner to its project teams to ensure that regional projects can be synchronized at the national level around sharable innovations and effective practices. BHEF also has developed the STEM Research and Modeling Network to provide open access to the dynamical systems modeling tool created by Raytheon that has benefited a number of STEM attainment projects. A similar modeling tool might improve our understanding of the broader attainment challenge and its complex interdependencies and dynamic nature - see item 3 in the Section 3.

The IMS Global Learning Consortium advances "learning impact by enabling the open foundation for seamless, agile and information-rich educational technology integration". Initially an open standards organization dedicated to interoperability among educational technologies, IMS has expanded its open mission by fostering an executive level, non-technical understanding of the necessary role of technology interoperability in achieving mission success, from the micro (institutional) to the macro (national) level of credentialing and attainment.

The BHEF and the IMS are examples of a nonprofit, nongovernmental organization built around relatively open governance models that guide a shared agenda and action plan to the mutual economic benefit of all stakeholder investors. Primary stakeholders are interested businesses and postsecondary institutions, in the case of the BHEF, and education providers, governments and suppliers of educational technologies and services, in the case of the IMS. BHEF and IMS are practicing many of the principles of an effective open economic governance process for a common good.

\section{A new angle on the attainment challenge: Open economic governance}

Affordable access to earning a trusted postsecondary credential has become nearly synonymous with the democratic value of equal opportunity. It is nonetheless tough to imagine postsecondary education as currently operated, governed, and regulated - becoming a fount of exponential growth in new economic and social wealth. Policy makers who find attainment at scale to be an urgent goal in the global race for intellectual capital are accordingly wary of leaving accountability to educators and are increasingly inclined to legislate or regulate desired results. For some insights into how to dampen current trust 
and three-way affordability tensions between educators and education's external investors, consider two examples of undeniable progress for the common socioeconomic good: the Internet and the World Wide Web.

Far from resembling the patchwork of gated communities that describes the organizations comprising today's credentialing marketplace, the common-good Internet is a network of networks that operates around the world as if it were one. The Internet is a paradigm of open, global self-regulation. It is controlled by no one entity, but continues to race forward in response to the common-good interests of all of its economic beneficiaries. Through a Web browser connected to the Internet, the Web becomes a self-service access point for a wealth of resources and services - some free and some for a fee, some open and some by permission. The result has been exponential growth in economic and social "wealth", both private and public - the same result that we seek from scaling up attainment!

The explosive growth of the Web/Internet in both scale and impact would not have been possible solely by "thinking globally and acting locally" (as networks and network applications proliferated randomly at micro levels around the world). Open cooperation and coordination were required. The Internet Society was created as a nonprofit, non-governmental open economic governance organization for selfregulating, advancing, and sustaining the Internet.

For those who are interested, here is a brief overview of the Internet Society, which:

- is a global cause-driven organization governed by a diverse (elected and appointed) Board of Trustees dedicated to ensuring that the Internet stays open, transparent and defined by you,

- is the world's trusted independent source of leadership for Internet policy, technology standards and future development,

- works to ensure that the Internet and the Web that is built on it:

- continue to develop as an open platform that empowers people to share ideas and connect in new and innovative ways, and

- serve the economic, social and educational needs of individuals throughout the world, today and into the future, and

- works with more than 55,000 members and nearly 90 Chapters around the world, as well as more than 130 Organization members, to achieve change through partnership and expertise in policy, technology and communications.

The Web/Internet is thriving precisely because of its common-good paradox: for Internet access, resources and communications to be available at unprecedented levels of self-service convenience, affordability and scale to both individual and organizational option requires globally coordinated economic governance processes to advance and sustain the policies and the infrastructure and application standards that permit the effective exercise of such options. Do the postsecondary credentialing opportunities that are increasingly available to individual option through an unprecedented number of institutions and nations require open, globally coordinated economic governance processes in order to scale up attainment, affordability, and accountability around the world? My answer is "yes!" We should learn not only to think globally while acting locally, but also to cooperate purposefully and openly within a global economic governance entity in order to achieve measurable global educational attainment results.

The credentialing marketplace should not be allowed to become what economists call a "tragedy of the commons", a phrase connoting the intentional or unintentional abuse of a common-good resource by some individuals or organizations to the detriment of the resource and all of its economic beneficiaries. For educational attainment to help advance and sustain our world, the educated (educators included) 
must find a way to save education from its own complacency, weak attainment productivity, lack of transparent accountability and failure to confirm through independent evaluation that students are learning to be lifetime learners as they work their way at scale through the credentialing pipeline and its myriad pathways.

Enter Elinor Ostrom, a 2009 Nobel Laureate in Economics. She was recognized for her work on the "economic governance of the commons". Her findings (for how best attempt to moderate the risks of a tragedy of the commons) favor an economic governance model having participation from each economic beneficiary group in the development and enforcement (by consensus) of "rules of the road" designed to advance and sustain common-good natural resources. Ostrom's work refutes the popular belief that economic governance for a common good should be left either to government (through regulation and legislation) or to entrenched non-governmental organizations.

\section{Education leadership commons}

Learning credentials are not natural resources, and education is historically entrenched and change resistant, unlike the Internet/Web marketplace. The attainment pipeline and credentialing marketplace nevertheless are common-good resources, and the attainment challenge, with its three-way affordability conundrum, is bearing down on "business as usual" in education. The time is right to look for innovative, structural, systemic solutions that might accomplish what extrapolation from the present is unlikely to accomplish. There are many ways to think about this possibility, but I propose the creation over the next few years of a nonprofit, nongovernmental, Ostrom-like, open, global economic governance entity for the credentialing marketplace - a global Education Leadership Commons. The collective purpose is to develop and advance open interoperability of credentialing services, processes, and accountability metrics - all through minimally intrusive, consensus-based, trusted, cause-driven cooperation.

The ELC would coordinate the micro-to-macro scaling of attainment, while helping to qualityassure learning outcomes and maintain the mutual affordability of credentialing processes to credential providers and their external investors. The ELC would be a safe-haven where progressive education leaders could collaborate with like-minded policy, business, student and foundation leaders to create (and provide stewardship for) rules of the road designed to advance educational attainment and its potential to exponentiate economic and social progress. The open ELC would face the challenge of rebalancing rights and responsibilities among the economic and social beneficiaries of the credentialing marketplace, while diminishing neither distributed educational autonomy nor expectations for individual student initiative and needs-tested funding from governments.

The ELC could be modeled along the lines of the Internet Society's successful governance mechanisms and standing working groups, such as the Internet Engineering Task Force and Internet Architecture Board. The ELC could be operationalized through standing working groups, their advisory or governance committees, and other nested and loosely-coupled efforts to advance and sustain educational attainment. Several of many possible ELC standing working groups are described below to illustrate how the ELC might function to address some of the challenges in the attainment conundrum.

(1) Establish an ELC standing Attainment Productivity Task Force to develop and maintain accountability processes and metrics for monitoring productivity in the credentialing marketplace in alignment with attainment goals and in ways that can be trusted by all of its economic beneficiaries, yet also support local autonomy. A starting point for such an agenda could be to: 
(a) Publish summary institutional-level productivity metrics formulated both to be universally transparent and to become meaningful benchmarks when compared within peer groupings. Such metrics, for example, might be as simple as the annualized ratios of:

(i) Credentials granted to unduplicated student headcount.

(ii) Operating expenses to credentials granted.

(b) Evaluate learning readiness independent of learning providers and governments and in the longitudinal aggregate to profile various population demographics and student bodies of peergrouped education providers. This could be accomplished, for example, via the data from periodic, age-based, independent, constructivist evaluations of students' critical thinking and basic fluency skills. (Such evaluations are already available from various sources, even at the global level via the work of OECD's AHELO project.)

(c) Agree on some subgroups of the adult population for which the proportion of trusted postsecondary credentials should and could be tracked in the aggregate and within most geopolitical boundaries. (The OECD and the NCES already report such metrics.)

(d) Develop guidelines for mapping attainment production to professional and workforce needs.

The simple metrics in 1(a) are applicable in a macro context. Within micro peer groupings defined in consideration of various geopolitical and education-sector boundaries, however, ever more detailed throughput metrics and cohort-based approaches could be formulated to drill down into those in 1(a), which are productivity metrics for today's credentialing processes at a micro level of throughput.

Similarly, the learning readiness evaluations referenced in 1(b) are meant, not to be one centralized series of multiple-choice assessments, but to be drawn from a pool of learning readiness evaluations that are independent of governments and education providers while admitting to age-based concordance among instruments of common purpose. Any number of other evaluations could be utilized by governments and institutions to track learning outcomes at various levels of content and geopolitical and education-sector peer groupings. The intent is not to stifle such micro activities, but to encourage them to roll up into a macro population that is as ready as possible for a lifetime of learning.

(2) Establish an ELC standing Competency-Based Learning Task Force (see Section 7). The purpose is to examine and identify effective, scalable practices that draw on competency-based learning and, to some degree, on independent evaluation of competency. Also examine how competencybased learning can be made more effective and less costly by applying some of the other strategies outlined in previous sections - the actionable accountability, common core redesign, flattening and flex strategies.

(3) Establish an ELC Information Strategy and Governance Task Force to advise on how to make key credentialing information and application resources ubiquitously accessible and useful and how to govern such resources (information governance for the common-good credentialing marketplace). We know, for example, that parents from low-income groups are frequently challenged by circumstance to nurture children who value and participate enthusiastically in education inside and outside the school. The haze that conceals the performance accountability of schools and colleges has political dimensions, but is also catalyzed by the difficulty of finding and accessing coherent information about education and the burgeoning library of online self-service learning resources. We need not only to market the value of credentials and attainment, but also to cut through the clutter that makes it difficult to learn more about access processes, net-tuition costs and the myriad 
pathways to educational attainment - and do so in context for interested students and families. (See the brief comments about the Educational Positioning System in Section 15.)

(4) Establish an ELC standing Economic Governance Task Force tasked with making participation in the credentialing marketplace mutually affordable and economically beneficial to education and education's external investors. This is a critical task, and will require identifying an economic lever that can be used to drive changes that are economically beneficial for each of the parties involved. How else could we expect all of the parties to accept transformational change? One obvious lever is government funding in the form of needs-tested financial aid (taking the form of promissory grants, loans and/or tax deductions). If such funding had to be earned by both the student and any education provider choosing to admit the student, then funding sources might be more inclined to stabilize and sustain their support. An earned right carries a responsibility and might be funded with greater unanimity than a pure right in the form of an entitlement.

\section{Funding sources for the leverage of earned, needs-tested aid}

That governments could shift their financial support for education to promissory aid that eventually flows directly to needs-tested students is an old idea that deserves renewed attention, even if it would be resisted in many geopolitical contexts. There are several differences proposed here that could make a difference. The most critical difference is that students would earn and re-earn promissory needstested aid through periodic evaluations of their learning readiness, but not through percentile ranking on any evaluations. The student who values education enough to submit to periodic evaluation of learning readiness would, without prejudice and as needed, have access to needs-tested promissory aid, while pursuing a form of happiness that is cultivated through higher learning and the self-respect it engenders.

Where government funding for attainment is declining and/or becoming more erratic, it might be possible to attract stabilizing funding from a "we-the-people" micro contribution infrastructure designed in collaboration with the ELC Economic Governance Task Force on the basis of the needs-tested, earned aid concept. According to recent public surveys, after all, most people value education as an individual good, even though it may appear unaffordable and opaquely unaccountable to many. The phrase "we the people", moreover, has again become a call for populist action on critical common-good problems. For example, Starbucks CEO Howard Schultz and his leadership team recently came up with a workable idea for creating new job opportunities while government funding and bank loans remain frozen. They have found a way to encourage and enable citizens to loan money to small businesses that have plans to pursue job-creating growth opportunities.

From some combination of government and other external sources, a start-up economic governance matrix of rights and responsibilities in the credentialing marketplace might then be based on responsibilities incurred by the financially supported student, responsibilities incurred by the education and learning evaluation providers that accept revenues from that student, and rights earned by the funding source(s) financially supporting that student. Below is one possible matrix of rights and responsibilities. Notice that the student is asked to submit periodically to the independent learning-readiness evaluation process described above in order to be eligible and remain eligible for a needs-tested promissory aid from government or other funding source. The value of the aid is estimated at birth from tax data and thereafter updated annually (Table 1).

The following matrix is based on the leverage of earned, needs-tested promissory aid. There are other possible leverage points or hooks for establishing trusted relationships among education providers and 
Table 1

Economic governance matrix of rights and responsibilities for the credentialing market

\begin{tabular}{|c|c|c|}
\hline Economic beneficiaries & Responsibilities & Rights \\
\hline Student & $\begin{array}{l}\text { Submit to periodic, independent, age-based, } \\
\text { constructivist evaluations of learning readiness } \\
\text { starting no later than, say, age } 15 \text { and persisting } \\
\text { for as long as the student wishes to qualify for a } \\
\text { means-tested aid. }\end{array}$ & $\begin{array}{l}\text { Defray the costs of services provided by } \\
\text { participating evaluation and education } \\
\text { providers from a promissory individual } \\
\text { account having needs-tested value estimated } \\
\text { annually from tax data, starting at birth. }\end{array}$ \\
\hline Evaluation provider & $\begin{array}{l}\text { Remain transparently independent from government } \\
\text { and education providers while privacy-securing } \\
\text { and maintaining evaluation data and concordance } \\
\text { tables for age-based learning-readiness evaluations } \\
\text { of like purpose. }\end{array}$ & $\begin{array}{l}\text { Bill a participating student's aid account } \\
\text { to help defray evaluation fees incurred } \\
\text { by the student. }\end{array}$ \\
\hline Education provider & $\begin{array}{l}\text { Track and openly report the shared accountability } \\
\text { metrics maintained for peer-group analysis by the } \\
\text { Attainment Productivity Task Force. Permit } \\
\text { privacy-secured extraction in the aggregate of } \\
\text { student and instructor data in support of } \\
\text { longitudinal research by funding sources. }\end{array}$ & $\begin{array}{l}\text { Bill a participating student's aid account } \\
\text { to help defray the cost of learning services } \\
\text { provided to the student. }\end{array}$ \\
\hline $\begin{array}{l}\text { Government and other } \\
\text { funding sources }\end{array}$ & $\begin{array}{l}\text { Commit to promissory needs-tested aid to help } \\
\text { students pay the costs of completing learning- } \\
\text { readiness evaluations and academic programs (from } \\
\text { participating evaluation and education providers). }\end{array}$ & $\begin{array}{l}\text { Extract privacy-secured data (from } \\
\text { participating evaluation and education } \\
\text { providers) for research into learning } \\
\text { readiness, attainment and their costs to } \\
\text { the economic beneficiaries of attainment. }\end{array}$ \\
\hline
\end{tabular}

their external investors by rebalancing the economic benefits of attainment among the parties involved. To be sure, there will be devils lurking in the details of how to integrate economic governance across various geopolitical and educational boundaries. The possible outcomes of the above approach, however, may clarify the potential value of such rebalancing efforts.

\section{Goals as outcomes for the Education Leadership Commons}

(1) Unbundle and virally expand the credentialing marketplace through open, voluntary compliance with technical (IMS) and non-technical (ELC) interoperability standards and protocols for extracting and transferring, by mutual consent, core data about educational outcomes and costs into a distributed longitudinal data system in which:

(a) Each participating education provider and independent evaluation provider has the right to capture selective privacy-secured data about its participating students and instructors as part of the contract among the parties involved.

(b) Each individual (e.g., student or instructor) controls a privacy-secured record and portfolio of personal educational accomplishments to share selectively with sources of funding for education and employment - again as part of a trusted relationship of potential mutual benefit to the parties involved. (See the Educational Positioning System in the next item.)

(2) Lay the framework for creating what Mike Mathews, a friend, has imagined as the Educational Positioning System of the future. The EPS gets its name by analogy to the myriad of applications 
that rely on the universally available and familiar Global Positioning System. The EPS could enable a suite of integrated technologies and massively interconnected data that would help ELC participants, especially students, to navigate the credentialing marketplace more effectively and efficiently. The student would know her educational position and have immediate access to opportunities and information to help chart informed pathways to an educational destination. The above matrix of rights and responsibilities would go a long way towards meeting the challenge of the unit-record database by giving students full rights to their privacy-secured individual educational data and to share that data throughout their lifetimes at their discretion.

(3) Encourage parents and, eventually, each of their children, to make postsecondary completion a shared life goal. We now know, after all, that early exposure to education is especially effective for improving educational readiness and attainment among low-income children. The ELC provides such encouragement as a corollary of using annual tax data, starting at a child's birth, to estimate and annually update the value of needs-tested promissory aid that can be earned as long as the child submits periodically to the learning readiness evaluation process.

(4) Support an open, digital learning cloud to provide gratis access (a) to comparative information about education (and all its implications for personal and collective success) and (b) also to informal, online, asynchronous learning opportunities and resources, such as free content and learning portfolios for students and instructors. The ELC's Information Sciences Strategy Group could help design these services.

(5) Focus and stabilize government funding for postsecondary education on needs-tested aid that has to be earned by individual commitments to learning-readiness evaluations on behalf of the attainment priority and its attendant value of actuating equal opportunity on a widespread basis.

(6) Meet market needs for professional and workforce expertise through employer credentialing incentives offering supplement value to earned aid (based on projected employment needs).

(7) Remove the already blurred distinctions between nonprofit public, nonprofit private, and for-profit private education providers by encouraging ELC participation at all levels of government and market needs (demand). Needs-tested aid is earned by the student, who has the discretion to spend it at any ELC-compliant institution interested in enrolling the student.

(8) Encourage education providers to compete in learning-centric accountability terms that are also learner-centric by providing options for an affordable, flexible and successful learning experience.

(9) Preserve accreditation's formative peer-review process for education provider self-improvement by a priori requiring adherence to the above voluntary, minimally invasive ELC external accountability protocols and metrics.

\section{Conclusion: Scaling attainment, affordability and accountability}

Not to engage the economic governance issue for the credentialing marketplace risks a tragedy of the commons. An open economic governance entity could earn trust from, and be mutually economically beneficial to, education providers and their external "investors" - students, families, governments, donors, employers and suppliers. Moving from concept to creation of an ELC, however, will require breaking down the parochial protections that limit many entrenched marketplaces, such as the credentialing marketplace with its thousands of "gated communities" protected by combinations of geopolitical, education-sector and education-provider forces. The Educational Positioning System is a succinct metaphor for bridging the gates with the immediacy of pathways constructed on demand to interconnect people, institutions, and relevant information. 
The time is right for the vested beneficiaries of attainment, especially visionaries and entrepreneurs, to create "trust-but-verify" economic governance cooperation as a means to accelerate education's pace in Wells' race between education and catastrophe. Millions of us want education to win. If government cannot provide the funding stability required for victory, then we the people should act - perhaps through a social networking micro-contribution mechanism. We are collectively the wind that could make tilting at the attainment windmill not only a priority, but also an achievable one. We need to summon the "wisdom of a willing crowd" - the leaders and visionaries who recognize that credentialing for attainment is a common good and know that it cannot be advanced solely from inside today's gated credentialing community.

Educational attainment is the holy grail that makes education's current credentialing practices a barrier to a more open, scalable credentialing marketplace, which, as a common good, could inspire individual and organizational commitment to learning that can help advance and sustain social, economic and environmental justice and to an open self-regulating economic governance entity (ELC) for scaling attainment, affordability, and accountability. We need to retire the rusty "iron triangle of access, costs and quality", which lost much of its relevance as new technology-enabled strategies demonstrated that enrollments and quality can measurably increase together, even as per-student cost structures decrease. We now need to marshal the cooperation and ideas required to demonstrate the mutual scalability of attainment, affordability and accountability. 